\title{
High-dose Aldesleukin Regimen
}

National Cancer Institute

\section{Source}

National Cancer Institute. High-dose Aldesleukin Regimen. NCI Thesaurus. Code C160045.

A chemotherapy regimen consisting of high-dose aldesleukin (recombinant human interleukin-2) that may be used in the treatment of kidney cancer and cutaneous melanoma. 